\title{
A relação governo e sociedade na gestão da política pública de esportes e lazer no governo do Estado de Pernambuco - 1999-2001: analisando o projeto "Idosos
em Movimento"
}

Maria da Conceição Araújo Batista

\begin{abstract}
Resumo: O presente estudo foi desenvolvido no âmbito do mestrado em Ciência Política e teve como objetivo analisar a relação Estado-sociedade no processo de formulação, implementação e gestão da política pública de esporte e lazer no Governo do Estado de Pernambuco, no período de 1999 a 2001. Aborda a questão da participação da sociedade civil nos processos decisórios de implantação, implementação e gestão da política pública de Esporte e lazer, a partir da consideração de que a adoção de mecanismos de democracia participativa na gestão das políticas públicas se constitui em elementos inovadores e contribuem para a redefinição da relação Estado-sociedade. Porém, as conclusões do estudo indicaram um distanciamento entre a proposta participativa do Governo estadual e o que efetivamente ocorreu ao nível da prática concreta do projeto "Idosos em Movimento".
\end{abstract}

Palavras-chave: democracia, participação, políticas públicas de esporte.

\section{Discutindo a democracia participativa}

No século XX, a Ciência Política foi marcadamente influenciada por uma linha de interpretação empírica voltada para descrever e explicar como funcionam as democracias, a qual abriu espaço para o ceticismo e a insatisfação que está presente em grande parte do pensamento contemporâneo.

Se, por um lado, os pluralistas e os defensores da democracia representativa liberal a entendem como o melhor arranjo institucional possível, por outro, essa mesma democracia é criticada por setores à direita e à esquerda. Porém, o cerne dessa discussão sobre o significado da democracia está centrado numa visão prospectiva: na democracia como meio ou como fim, na natureza, nas atribui-

Movimento, Porto Alegre, v. 11, n. 3, p. 27-48, setembro/dezembro de 2005 
ções e responsabilidades do Estado e nas relações entre Estado-sociedade.

Mesmo correndo o risco de reducionismo desse embate, podemos classificar tais posições em dois grandes grupos: de um lado, os que advogam uma concepção minimalista de democracia, em que a mesma é e deve ser apenas um método para constituir governos desprovidos de qualquer atributo finalístico; ${ }^{1}$ e, de outro, estão os que, reconhecendo também a superioridade da democracia enquanto regime político, postulam a transformação do Estado e da sociedade a partir da e com a democracia real.

Para os autores que entendem a democracia enquanto método voltado apenas para as regras do jogo, despido de conteúdo humanista, a condição possível do governo democrático, fundada em Estados-nação, está confinada ao modelo representativo, dada a impossibilidade do exercício direto da democracia. Porém, não abrem mão da concepção de democracia fundada na soberania popular. Para esses autores, democracia representativa significa que decisões que dizem respeito à coletividade inteira não são tomadas diretamente por ela, mas por pessoas eleitas para isso.

Os pressupostos teóricos abordados referem-se à "concepção dominante ${ }^{\prime 2}$ da teoria democrática na Ciência Política nos últimos 50 anos, onde podemos perceber que a participação tem um papel menor, limitando-se ao voto para escolha de representantes (que tomam as decisões), bem como à proteção do indivíduo contra decisões arbitrárias e à proteção de seus interesses privados.

Porém, numa outra direção, alguns estudiosos da teoria democrática buscaram revalorizar a participação política, colocando a participação de volta ao centro da teoria democrática. Um dos estudos de expressão nesse campo é o de Carole Pateman, denominado Participação e Teoria Democrática, publicado em 1970.

A autora pretende demonstrar a possibilidade de efetivação da democracia participativa nas sociedades modernas, porém não está preocupada em criar um modelo institucional de governo, mas discutir sobre o papel da participação numa teoria da democracia moderna e viável e sobre as possibilidades de a mesma ser exercida efetivamente pelos cidadãos.

1 Seu principal expoente é Joseph Schumpeter, com seu livro Capitalismo, Socialismo e Democracia, publicado em 1943, cuja teoria influenciou grande parte das teorias democráticas posteriores.

2 Expressão utilizada por Sartori (1996, p. 06).

Movimento, Porto Alegre, v. 11, n. 3, p. 27-48, setembro/dezembro de 2005 
A autora constrói sua teoria de democracia participativa a partir das contribuições dos autores da teoria democrática, como Jean Jacques Rousseau, John Stuart Mill³ e G.H. D. Cole. Ela reconhece esses autores como os teóricos da democracia participativa; e a contribuição dos mesmos reside no fato de que o conceito de democracia indica "algo muito mais amplo do que uma série de arranjos institucionais em nível nacional" (PATEMAN, 1992, p. 52).

Pateman, nas suas reflexões, critica principalmente a perda dos ideais democráticos clássicos, sobretudo a igualdade, que se reduz à igualdade formal perante a lei.

A autora defende a participação dos indivíduos nos processos de tomada de decisão, pois essa situação geraria uma igualdade política que terminaria por aguçar o senso de responsabilidade dos indivíduos quanto às conseqüências e à aceitação das decisões coletivas. Para ela, a principal função da participação é a educativa, ou seja, existe um processo de retroalimentação entre a participação e a aquisição dos atributos necessários para essa participação.

Pateman afirma que a existência de uma forma de governo democrática pressupõe a existência de uma sociedade participativa em que todos os sistemas de tomada de decisão tenham sido democratizados. Essa socialização dos sistemas políticos deve ocorrer em todas as estruturas de autoridade, sejam governamentais ou não, porém chama a atenção para o caráter fundamental da indústria (que considera uma esfera de atuação política por excelência), que contribuiria de forma decisiva para o processo de construção da cidadania, ao ampliar as possibilidades de participação efetiva dos indivíduos em outras esferas da sociedade.

Um outro autor de importância nessa discussão da democracia participativa é Crawford Macpherson. Para ele, a democracia participativa ganha relevância a partir dos movimentos sociais nos anos 60 e difundiu-se pela classe trabalhadora em resposta às insatisfações com as relações de trabalho existentes. Podemos afirmar que a preocupação central do autor refere-se ao futuro de um sistema de governo com mais participação para as nações liberaldemocráticas do ocidente.

Macpherson parte do pressuposto de que a democracia não se reduz a um mecanismo apenas para escolher e autorizar go-

3 É importante deixarmos claro que consideramos tanto Rousseau como Mill como autores de tradição liberal. E a referência as suas obras ocorre devido às contribuições dos mesmos quanto aos princípios participativos para a teoria democrática.

Movimento, Porto Alegre, v. 11, n. 3, p. 27-48, setembro/dezembro de 2005 
vernos ou, de algum outro modo, obter leis e para que sejam tomadas decisões políticas. Democracia é muito mais que isso. Ela é vista "como uma qualidade que penetra toda a vida e todas as atividades, como um tipo de sociedade no conjunto inteiro de relações recíprocas entre as pessoas que constituem a nação ou outra unidade" (1978, p.13)

Para Macpherson, se a democracia é, por definição, o governo do povo, como poderá o povo governar sem participar? Nesse sentido, o povo não governa sem participação, e vai além afirmando que "a baixa participação e a iniqüidade social estão de tal modo interligadas que uma sociedade mais equânime e mais humana exige um sistema de maior participação política" (1978, p.98).

Ele reconhece que a participação por si só, não afasta todas as iniqüidades sociais, mas atribui um caráter ético à democracia participativa ao perceber uma correlação positiva entre participação e igualdade (BRANDÃO, 1997). No entanto, o autor não descarta a democracia representativa, algum tipo de representação terá que existir. Nesse sentido, a democracia participativa deveria ser ao mesmo tempo direta e representativa.

A preocupação central do autor sobre os delineamentos da democracia participativa nas sociedades modernas não se refere ao seu funcionamento, mas sobre como chegar a ela, como atingila. Portanto, assegura que, para se chegar à democracia participativa, faz-se necessário atender a dois requisitos: a mudança da imagem do homem como consumidor, e a diminuição das desigualdades econômicas e sociais.

Um outro autor que traz contribuições importantes é o neomarxista Carlos Nelson Coutinho, profundo conhecedor da realidade brasileira. A sua análise prende-se ao contexto brasileiro na década de 80 e incide sobre o reconhecimento do "valor universal"4 da democracia como o caminho para a construção de uma sociedade socialista no Brasil.

Segundo o autor, nos primeiros regimes liberais a participação era restrita, o Estado aparecia praticamente como o único

4 Para o autor, muitas das conquistas democráticas modernas se desenvolveram e consolidaram no quadro da ordem capitalista. Portanto, nem objetivamente, com o desaparecimento da sociedade burguesa, nem subjetivamente, para os atores empenhados nesse desaparecimento, perdem o seu valor universa/ muitas das objetivações nhados nesse desaparecimento, perdem o seu valor universa/ muitas das objetivaçoes
ou formas de relacionamento social que compõem o arcabouço institucional da ou formas de relacionamento social que compõem o arcabouço institucional da
democracia política. O qualificativo universal refere-se ao fato de que essas objetivações democracia política. O qualificativo universal refere-se ao fato de que essas objetivações democráticas se manifestam em diferentes

Movimento, Porto Alegre, v. 11, n. 3, p. 27-48, setembro/dezembro de 2005 
ator político coletivo. No final do século XIX e início do século XX, graças às lutas das classes trabalhadoras, foram conquistados o sufrágio universal e, mais tarde, o sufrágio feminino e a formação de sindicatos.

Esse processo, que o autor denominou de socialização da política, não se restringiu à classe operária, outros grupos e camadas sociais passaram a se organizar. Até a "burguesia viu-se obrigada a criar organismos coletivos fora do âmbito do Estado, para competir com as associações operárias e populares" (COUTINHO, 1992, p.25).

Para o autor, essa democratização ou socialização da política ${ }^{5}$ se expressa na ampliação da esfera pública, o que tem gerado, ao mesmo tempo, um problema e os meios para sua solução. O problema reside em superar a contradição existente entre a socialização da participação política, por um lado, e, por outro, a apropriação não social dos mecanismos de governo da sociedade. Conforme destaca o autor, para a realização das potencialidades abertas pela crescente socialização do homem, a superação da alienação econômica apresenta-se como condição necessária, mas não suficiente para essa realização, o que implica o fim da alienação política, que poderia tornar-se realidade através da reabsorção dos aparelhos estatais pela sociedade que os produziu e da qual eles se alienaram através de uma nova democracia, a democracia de massas (COUTINHO, 1992).

O autor faz questão de destacar que a construção de uma sociedade autônoma e autogovernada, a partir da superação da alienação política, não se restringe ao projeto comunista, sendo também fruto do projeto democrático moderno através do contrato social de Rousseau.

Coutinho (1992), a partir das reflexões de Rousseau, coloca que este considerava a formação de associações particulares um obstáculo para o desenvolvimento de uma "vontade geral", que ele julgava ser pressuposto básico de uma ordem democrática. Porém, também advertia que, caso essas associações existissem, o melhor seria sua proliferação.

O autor ao trazer essas reflexões para o cenário da sociedade capitalista moderna, afirma que ambas as posições são problemáticas. Se, por um lado, a socialização da política manifestou-se

5 Segundo o autor, a socialização da política é a ampliação do número de pessoas e de grupos empenhados organizadamente na defesa de seus interesses (COUTINHO,1992).

Movimento, Porto Alegre, v. 11, n. 3, p. 27-48, setembro/dezembro de 2005 
através da multiplicação de associações particulares (partidos, sindicatos, movimentos sociais), com interesses setoriais limitados, levando ao liberal corporativismo, mediado pelo mercado, por outro a negação desse pluralismo em nome de uma pretensa unidade, como no "socialismo real", provocou uma situação em que a vontade geral se impôs à "vontade de todos".

Entretanto, assegura Coutinho, ambas as possibilidades não promovem a superação da dominação burguesa sobre o Estado. Na primeira possibilidade, a supervalorização do pluralismo tem levado à atomização dos indivíduos e grupos e à conseqüente fragmentação da sociedade, de forma a defender interesses que não privilegiam o interesse público; e a segunda, nega a possibilidade de o indivíduo participar da cena política, submetendo-o à vontade geral.

Para o autor, deve-se buscar uma posição intermediária que possibilite a articulação entre o predomínio da vontade geral e a conservação do pluralismo. Nesse sentido, ele assegura que a socialização da política já esboçou as soluções institucionais para essa articulação que se realizará através da democracia de massas, a qual prevê a integração entre os organismos da democracia de base e os mecanismos da democracia representativa. Sobre a relação entre democracia de massas e democracia liberal, Coutinho considera que não é uma relação de negação, mas de superação dialética: a primeira "conserva e eleva a nível superior" às conquistas da segunda (COUTINHO, 1992, p.36).

Com base nos diferentes autores de tradições teóricas aparentemente tão diversas, é possível identificar pontos de convergência. Porém é importante ressaltarmos, inicialmente, que eles tratam a idéia de democracia participativa conduzidos por móveis diferentes. Coutinho escreve sobre a democracia em diálogo com a tradição marxista. Para ele, a questão democrática está inserida num contexto de transformação e mudança da sociedade, ou seja, a democracia é vista, não como um caminho para o socialismo, mas sim como o caminho do socialismo. Já Macpherson, expõe suas idéias polemizando com a tradição liberal. Pateman dialoga com a tradição liberal, embora discuta experiências marxistas.

Os três autores se aproximam pelo fato de demonstrarem preocupação com a instauração de democracias com ampla participação popular nas sociedades modernas.

Pateman, por exemplo, preocupa-se em provar a viabilidade da democracia participativa nas sociedades modernas, mas não

Movimento, Porto Alegre, v. 11, n. 3, p. 27-48, setembro/dezembro de 2005 
apresenta nenhum modelo institucional. Já Macpherson, discute tanto a viabilidade da democracia participativa como considera fundamental estabelecer um possível modelo organizacional. Coutinho difere dos dois porque acredita que as condições para a instauração de uma democracia de base com ampla participação popular já existem, devido ao processo de socialização da política. Macpherson e Pateman convergem quando se opõem à "corrente empírica da democracia," dominante na Ciência Política na maior parte do século XX, ao passo que Coutinho fica à margem dessa discussão. Macpherson aproxima-se de Coutinho quando debate sobre a necessidade de articulação entre democracia direta e democracia representativa. Essa discussão não é tratada na obra de Pateman.

\section{A participação e as mudanças na relação Estado-Sociedade}

A relação Estado-sociedade, no Brasil, foi marcada por traços autoritários em que o Estado sobrepôs-se à sociedade. Nesse sentido, até o final da década de 70, o modelo de gestão governamental caracterizou-se pela centralização do poder decisório e executivo no Governo Federal assumindo características marcadamente tecnocráticas, autoritárias, clientelistas e patrimonialistas (SILVA, 2002).

Para alguns autores, esse processo se altera substancialmente no decorrer da década seguinte, devido às transformações no modus operandi da administração pública, com a introdução de alguns componentes democráticos na estrutura hierárquica, bem como com as mudanças no desenho político institucional.

Os primeiros governos da chamada Nova República ${ }^{6}$ atribuíram prioridade aos programas de estabilização econômica, descaracterizando importantes itens da agenda pública, sobretudo aqueles relacionados aos programas sociais. A urgência atribuída ao controle da inflação frustrou as expectativas da população, depositadas no governo da aliança democrática, de atenuar as desigualdades sociais existentes, provocando um distanciamento cada vez maior entre o Estado e a sociedade.

Nesse sentido, paradoxalmente, no decorrer dos anos 80, sobretudo nos anos 90, no cenário de afirmação das políticas neoliberais, a América Latina experimentou inegáveis avanços políticos.

6 Governos Sarney e Collor.

Movimento, Porto Alegre, v. 11, n. 3, p. 27-48, setembro/dezembro de 2005 
Se, do ponto de vista econômico, a década de 80 representou a chamada década perdida, no plano político, consolidou-se um quadro institucional básico de democratização. Devido às pressões de uma sociedade civil mais ativa e organizada, foram sendo criados novos espaços públicos de negociação, e as práticas participativas associadas a uma mudança qualitativa da gestão ganham visibilidade pública e repercutem na sociedade.

A criação e o fortalecimento desse novo espaço público, chamado de esfera pública não-estatal (conselhos, fóruns, orçamento participativo), representam um novo marco nas relações entre o Estado e a sociedade civil ao fomentar as experiências da chamada Democracia Participativa. ${ }^{7}$ Essas experiências de participação nos atos do governo ou na fiscalização deles, de forma direta ou semiindireta, ${ }^{8}$ têm introduzido uma nova forma de gestão dos interesses públicos orientados pela criatividade, transparência e participação ( SILVA, 2002).

Essas mudanças experimentadas com a redemocratização do país exigiram transformações no ordenamento político-institucional em vigor e a consolidação de um Estado capaz de assegurar a ação política transformadora dos cidadãos. Nesse sentido, o princípio da participação direta dos cidadãos na gestão pública institucionalizouse na Constituição de 1988, que tem como norma geral: "todo poder emana do povo, que o exerce por meio de representantes eleitos ou diretamente, nos termos destas constituição"(CF., 1998, Artigo $1^{\circ}$ parágrafo único).

Silva (2002), afirma que, no debate político atual, dois projetos se destacam: o democrático liberal e o democrático popular. No primeiro caso, há uma preocupação com a modernização e a diminuição da máquina estatal, o que caracteriza uma prática política neoliberal. No segundo caso, busca-se favorecer a organização da sociedade civil, promover uma reestruturação dos mecanismos de decisão e criar possibilidades de intervenção social na elaboração e implementação das políticas públicas. Em conseqüência desses projetos políticos, o entendimento do conceito de participação apresenta-se diferenciado. Na perspectiva do projeto democrático liberal, o Estado se desonera dos problemas sociais e a participação limita-se aos poucos representantes que atuam nos con-

7 Pateman, Carole (1992), Tavares da Silva, Gustavo (2002).

8 Na democracia semidireta, os cidadãos participam da esfera pública por meio de representantes, em organismos colegiados ou executivos, da entidade que integram, ou pela mediação de uma ou mais pessoas, como é o caso dos conselhos e comissões (LYRA apud MACHADO, 2002, p.33).

Movimento, Porto Alegre, v. 11, n. 3, p. 27-48, setembro/dezembro de 2005 
selhos, nas comissões e associações. No projeto democrático popular, a participação é vista como alternativa para construir uma nova noção de bem público e de responsabilidade pública que se traduz em novas formas de governar, representadas pela introdução de mecanismos mais transparentes e sistemáticos de decisão fortalecendo a legitimidade do sistema governamental e administrativo.

A participação assume, então, papel fundamental para a democratização das relações de poder na sociedade. Nesse sentido, podemos dizer que a participação ampliada se consolida na medida em que viabiliza a capacidade dos movimentos organizados da sociedade civil para influenciarem, direta ou indiretamente, a formulação e a gestão das políticas públicas (JACOBI, 2000).

Esse processo participativo modifica as relações entre o Estado e a sociedade civil e introduz uma mudança paradigmática na gestão pública, antes baseada numa estrutura vertical de autoridade, para uma estrutura de redes interativas horizontais, estabelecendo as condições para o surgimento de uma nova contratualidade que se expressa com base na eqüidade e na participação popular descentralizada e pluralizada.

Porém, cabe também enfatizarmos que a participação tem limites, ela não é panacéia para todos os problemas. É preciso termos claro que o Estado é resistente à participação ampliada e que os programas muitas vezes limitam-se à participação restrita ou instrumental, não demonstrando preocupação com uma concepção de eqüidade. ${ }^{9}$

Jacobi (2000), ao falar da ampliação da conquista de espaços participativos e da institucionalização dos mesmos, chama a atenção para o "risco"10 de ela se transformar em referencial para garantir a execução eficiente de programas de compensação social no contexto das políticas de ajuste estrutural, de liberalização da economia e de privatização do patrimônio público. Um outro aspecto a ser considerado é que a implementação de propostas participativas nas gestões encontra uma série de barreiras como a falta de agilidade nas decisões, a ausência de canais administrativos que dêem garantia institucional à interação com os grupos organizados

9 A noção de eqüidade não se limita à distribuição dos recursos; nesse caso; referese à distribuição do poder, inclusive do poder de decidir sobre a alocação dos mesmos.

10 Grifo nosso. As práticas que tornam legítima a participação cidadã na gestão muitas vezes associam-se à necessidade de tornar mais eficiente a ação governamental, o que é uma contradição, em virtude do fortalecimento das políticas de corte neoliberal que promovem a desqualificação do papel do Estado.

Movimento, Porto Alegre, v. 11, n. 3, p. 27-48, setembro/dezembro de 2005 
e com os movimentos populares e resistências tecno-burocráticas. É importante também estar atento à formação de um duplo poder, que poderá reproduzir práticas corporativas que venham a interferir no universalismo de procedimentos, bem como o controle estatal sobre a ação cidadã.

A partir desses elementos, consideramos, então, que é fundamental que os sujeitos sociais estejam atentos a sua forma de participação para poderem avaliar a real influência que podem exercer, pois a participação recebe conotações diferentes de acordo com a sua inserção nos diversos momentos da gestão e execução das políticas, ou seja, participar na solução de problemas não é o mesmo que intervir nas decisões de interesse público.

Consideramos que superar a lógica clientelista que prevalece na relação Estado-sociedade, constitui-se num dos maiores desafios da atual conjuntura política brasileira. Sabemos que inúmeros espaços de negociação dos interesses públicos foram criados e conquistados em várias áreas das políticas públicas e na realização de projetos em parceria com a comunidade, e que apontam para o potencial inovador dessas experiências como meio para agilizar as mudanças sociais pretendidas. Porém, esse impacto transformador ainda é pouco expressivo para o conjunto da sociedade brasileira. Nesse sentido, é preciso que se construa uma soma positiva entre Estado e sociedade civil que permita a desprivatização do público ${ }^{11}$ e sua conseqüente publicização, bem como a construção de uma cidadania ativa.

\section{Definindo os parâmetros teórico- metodológicos}

A partir do entendimento da metodologia como elemento constituinte de todo o processo da pesquisa e não apenas como simples procedimento metodológico para apreensão da face empírica da realidade, mas que guarda uma discussão problematizante sobre os limites da ciência, de forma a permitir opções mais seguras que possibilitem uma explicação da realidade, o método não aparece como o maior problema. A questão central refere-se ao entendimento da realidade, na medida em que as diferentes formas de interpretação da realidade trazem em seu bojo uma teoria que a explica.

11 O Espaço público no Brasil, ao longo da história, foi confundido com o governamental e adquiriu características socialmente excludentes para o conjunto da população, exceto para frações do poder oligárquico e da classe dominante.

Movimento, Porto Alegre, v. 11, n. 3, p. 27-48, setembro/dezembro de 2005 
Com base nessas preocupações e a partir do entendimento da realidade como algo dado e construído, ponto de vista que compartilhamos com Pedro Demo (1995), adotamos como opção metodológica, para o desenvolvimento desta pesquisa, a dialética históricoestrutural.

Nesse sentido, esta pesquisa buscará captar a realidade dinâmica e complexa do objeto empírico através da observação do concreto, passando pelo abstrato do pensamento, para retornar ao real (concreto), agora à luz de uma explicação específica. A utilização desse método possibilita penetrar "no mundo dos fenômenos através de sua ação recíproca, da contradição inerente ao fenômeno e da mudança dialética que ocorre na natureza e na sociedade" (FERREIRA, 1998, p.100).

Esse aporte metodológico permite pensar a realidade social enquanto totalidade concreta. Como um todo estruturado em curso de desenvolvimento que possibilita significância para o fato ou conjunto de fatos. Na perspectiva desse entendimento, a totalidade constituiu-se uma categoria fundamental para a aproximação do real. "A produção do conhecimento não é um processo que se constrói " a partir do isolamento das partes do todo, mas toma o todo, em suas articulações necessárias e contraditórias, como fundamental" (FERREIRA, 1998, p.100).

Tomando como referência os argumentos acima, foram definidos como procedimentos metodológicos para o levantamento dos dados empíricos:

1) Pesquisa documental.

2) Entrevista semi-estruturada.

A discussão mais procedimental da pesquisa de campo, encontra-se resumida a seguir.

\section{Construção dos resultados do estudo}

Neste capítulo apresentamos os resultados do nosso estudo que foram obtidos a partir da pesquisa de campo e estruturados em três momentos distintos:

a) análise da conjuntura política; b) descrição do projeto e c) análise das concepções e práticas

a) No primeiro momento apresentamos o cenário político de surgimento do projeto que foi construído com base em entrevistas com cientistas políticos, no exame de material jornalístico e em documentos produzidos pela equipe de governo e pelos colaboradores. Nesse momento, procuramos situar o projeto de go-

Movimento, Porto Alegre, v. 11, n. 3, p. 27-48, setembro/dezembro de 2005 
verno no que se referia à concepção de gestão das políticas públicas adotadas.

b) Neste momento, tratamos da descrição do projeto "Idosos em Movimento"12 no bojo do cenário político apresentado no qual procuramos evidenciar a estrutura em que o mesmo se insere, o seu desenvolvimento e funcionamento. Este capítulo foi construído com base em documentos produzidos pela equipe da Diretoria de Esportes (documento da concepção do projeto) e em portarias do Diário Oficial do Estado.

c) São apresentadas as análises das treze entrevistas realizadas a partir de dois grupos de sujeitos:

1) os gestores, representados pela letra G e nomeados como G1, G2, G3, G4 e G5;

2) as lideranças dos grupos de idosos a quem o projeto atende, foram nomeados como L1, L2, L3, L4, L5, L6, L7, L8.

\section{Apresentação dos resultados da investigação}

\section{A gestão do projeto na ótica dos sujeitos envolvidos}

Neste item, apresentaremos as análises das entrevistas que foram construídas em torno da categorização de dois eixos temáticos, a saber:

1) A concepção de participação que se expressa na relação estabelecida entre o Governo e a sociedade na formulação, implementação e gestão do projeto "Idosos em movimento"

2) Os mecanismos de gestão participativa existentes e a sua contribuição para a democratização das relações Estado-sociedade.

$\mathrm{Na}$ análise do primeiro eixo temático, foi possível identificarmos que as concepções de participação dos gestores e das lideranças dos grupos de terceira idade se apresentaram extremamente heterogêneas e contraditórias; porém, apesar disso, conseguimos apreender um aspecto em que essa multiplicidade de percepções apresenta uma convergência, qual seja: concepção de

12 Este projeto vem sendo implementado pelo Governo do Estado de Pernambuco desde 1999, e o tomamos como objeto empírico do estudo, a partir da consideração de alguns aspectos entre os quais: a questão do envelhecimento apresentar-se como tema de importância para as políticas públicas; o mesmo não se adequar ao modelo do esporte de rendimento; era visto como o projeto modelo da Diretoria de Esportes do Estado.

Movimento, Porto Alegre, v. 11, n. 3, p. 27-48, setembro/dezembro de 2005 
participação restrita à fase de execução das atividades.

Eu acho que a estratégia é justamente a de levar uma atividade física sistemática para esses idosos. (...) Eles têm, em dias alternados, um tempo de aula com conteúdos de dança dos jogos da ginástica (G3)

A minha participação também, como a de todos aqui do nosso grupo, é uma participação muito boa, muito ativa. Nós participamos aqui nas segundas e nas quartas-feiras pela manhã. (L6)

No discurso abaixo, vamos perceber que as concepções de participação são as mais díspares:

participar, pra mim é opinar, é sugerir, é criticar, é conseguir externar a sua opinião, ter a liberdade de discutir e de opinar (Gl)

participação é justamente quando você convoca o maior $n .^{\circ}$ de pessoas do segmento. Participação é não discriminar (G2)

Participação é a gente ser atuante, participar de todos os eventos, projetos, é ser participante, atuante mesmo ( $\mathrm{Ll}$ )

É a gente vir pra cá, a gente se distrai, sai dos aperreios de casa, passa o dia aqui tranqüilamente todos unidos (L7)

Um outro aspecto identificado nas nossas análises, que não consideramos uma convergência, mas uma tendência, refere-se a uma preocupação com a idéia de legitimação que perpassa o conceito de participação. De um lado, o Estado buscando essa legitimidade e, de outro lado, a sociedade confirmando essa legitimidade, como veremos nos depoimentos a seguir.

Primeiro você escolhia os municípios em que iria implantar e depois ia lá fazer um bate papo com eles, informava para então eles poderem entender o que era aquele projeto que eles iriam fazer. E a aceitação foi maravilhosa. Houve realmente uma aceitação bastante grande da população(G2).

Na ótica dos idosos, é possível percebermos que essa estratégia agradou na medida em que se sentiram co-partícipes desse processo:

Nós começamos a participar do princípio. Houve várias reuniões com a direção da Secretaria de Esporte. Eles fizeram visitas a cada grupo (...) Então neste primeiro contato, eles vieram visitar os grupos, e o pessoal da diretoria estabeleceu o que queria e o que estava fazendo. A gente teve este contato. Não foi logo assim pegando e jogando a ginástica não (L2).

Segundo eixo de análise: Os mecanismos de gestão participativa existentes e sua contribuição para a democratização das relações Estado-sociedade.

Para realizar a nossa análise, usamos o quadro modelos de gestão pública ${ }^{13}$ tomando como referência os aspectos: base decisória, metodologia e definição de prioridades.

Movimento, Porto Alegre, v. 11, n. 3, p. 27-48, setembro/dezembro de 2005 
Quadro - Modelos de Gestão Pública

\begin{tabular}{|ll|}
\hline Tradicional/conservador & \multicolumn{1}{c|}{ Alternativo/Inovador } \\
\hline Base decisória: & Base decisória: \\
- Tecnocracia & - Técnicos/Comunidade \\
- Discurso da participação & - prática da participação \\
- Centralizada/dispersa & descentralizada/concentrada \\
& Metodologia: horizontal \\
Metodologia: vertical & - Participativa \\
- Legalismo & - Autodeterminação, \\
- Avaliação quantitativa & legitimação \\
& - Avaliação quantitativa e qua- \\
Definição de prioridades: & litativa \\
- Centralizada pela Burocracia & Definição de prioridades: \\
- Baseada nas prerrogativas do & - Descentralizada, baseada na \\
Executivo & Parceria/Compromisso com a \\
& comunidade \\
\hline
\end{tabular}

Fonte: Tavares da Silva, 2002

Com relação à base decisória, é possível afirmar que é tecnocrática e nela a participação dos idosos tem ocupado um plano secundário.

(...) para poder a gente partir para saber o que é que a gente queria trabalhar com estes idosos em relação à área de esporte, que é a nossa área específica, tivemos que fazer uma sondagem. Fizemos um questionário, enviado a todas as prefeituras, onde fazíamos uma pesquisa sobre que tipo de trabalho desenvolviam e se existiam algum trabalho na área de esporte e lazer, (...) constatamos que não existia absolutamente nada na área de Esporte; (...). Daí a gente se reuniu e fizemos uma proposta de trabalho cujo eixo principal foi a criação do projeto "Idosos em Movimento" (...). E daí surgiram vários festivais e várias outras ações em relação a esse segmento (G2)

Do ponto de vista dos idosos, os depoimentos vão evidenciar que a maioria é apenas informada das definições:

Como foi criado, pelo menos eu não participei (...) isso foi mais com o diretor, com pessoas mais capacitadas, então já veio para nós a programação já organizada, e perguntaram se a gente queria participar (Ll)

13 Para maior conhecimento a respeito das categorias utilizadas ver, Tavares da Silva (2002).

Movimento, Porto Alegre, v. 11, n. 3, p. 27-48, setembro/dezembro de 2005 
É possível percebermos nos depoimentos dos gestores um discurso preocupado com a participação:

Deixe-me ver, sempre se teve uma coisa muito confusa em nível do que significa participar e, às vezes, a gente é levado a reunir pessoas, apresentar uma proposta e achar que houve a participação (Gl)

Na ótica dos idosos, o que vamos perceber é que, efetivamente, eles não participaram da discussão sobre a implantação do projeto "Idosos em Movimento":

Não houve discussão, não, no nosso grupo, essa discussão veio lá do setor da diretoria (...) pra ver quais são os grupos que têm mais freqüência(...) pra ser implantado (L6)

Conforme a análise do projeto "Idosos em Movimento", foi possível apreender que as decisões são tomadas de cima para baixo, evidenciando uma metodologia vertical em que se busca informar ou consultar a comunidade sobre as questões já definidas a priori, de acordo com o depoimento dos gestores:

A gente tem reuniões mensais, desde o início do ano (...) para fazer uma discussão, temos que traçar diretrizes; não se pode chegar a uma reunião, principalmente com idoso, e dizer assim: vamos agora falar sobre os jogos; e o que é que vocês querem que a gente faça? O esquema, como toda proposta, tem que ter uma linha, tem que ter uma diretriz, não se cria do nada, tem se que chegar com uma proposta e, em cima daquela proposta, reela-borar novas propostas (...). Tudo, ou seja, muitas coisas eles sugerem, claro, mas a maioria das coisas a gente traça, leva para eles (G2).

Na ótica dos idosos, vamos perceber que as reuniões concentram-se nos aspectos técnicos referentes a organização dos jogos solidários da terceira idade:

Elas acontecem mensalmente, mas, quando chega mais perto dos jogos, às vezes são duas, dependendo da condição de que precisem. (L2)

Não, isso aí não. Até agora, de idosos em movimento, não. De idosos em movimento, não houve ainda essa reunião. A reunião que há é quando elas convidam, quando querem fazer um evento, não é? Então vai ter agora quando haverá os jogos solidários (L3)

Os idosos se manifestavam livremente, porém o controle das discussões nas reuniões cabia aos gestores, não evidenciando mecanismo de controle que pudesse dar garantias aos idosos de que as questões definidas naquelas reuniões realmente se efetivariam:

A gente podia propor qualquer coisa. Agora eles lá escutavam e tiravam as coisas melhores. Às vezes uma pessoa propõe uma coisa, outro, outra, e eles vêem que dá certo, vêem que não dá, então tiram a melhor (L5)

Movimento, Porto Alegre, v. 11, n. 3, p. 27-48, setembro/dezembro de 2005 
Nos depoimentos dos gestores foi possível perceber uma preocupação com a avaliação voltada para aspectos quantitativos em detrimento de avaliações mais qualitativas, preocupadas com a eficácia das políticas públicas e os seus resultados, a médio e longo prazo, na melhoria das condições de vida da sociedade:

a gente fazia algumas visitas nos dias de reunião, também era um momento em que a gente via como era que tava o idoso em movimento. Tem muita gente aqui que participa (...) a gente colocara que eles não podiam perder o espaço, era importante a assiduidade, a pontualidade, pra que o projeto continuasse, porque, se a gente não tivesse o quantitativo, teríamos que mudar pra outro grupo. Então é importante saber se realmente eles estavam correspondendo ao que tava se oferecendo a eles (G3)

O que percebemos na gestão do projeto "Idosos em Movimento" é que as decisões são centralizadas pela burocracia, baseadas nas prerrogativas do Executivo.

\begin{abstract}
(...) tem coisas que a gente tem que saber separar, tem coisas sobre as quais a gente tem que saber tomar decisão, saber o que é melhor pro Estado. E a outra é deixa-los discutir permitir que cheguem a um denominador comum, entendeu? Tem programa que não precisa (...) (G5)
\end{abstract}

\title{
Considerações finais
}

O estudo teve por objetivo identificar como o discurso participativo do Governo de Pernambuco se materializou no âmbito da política pública de Esporte e Lazer através do projeto "Idosos em Movimento". Nesse sentido, procuramos percorrer um caminho teórico-metodológico que possibilitasse chegar ao final do trabalho respondendo à questão central do estudo que se colocava em torno da indagação: como os princípios de participação / democratização propostos pelo governo estadual se expressam na política pública de esporte e lazer através do projeto "Idosos em Movimento"?

A partir das referências teóricas norteadoras do estudo e após as análises dos dados, chegamos ao final do mesmo com algumas constatações:

As concepções de participação convergiram para uma visão restrita à fase de execução das atividades;

Preocupação por parte dos gestores em promover a legitimação das ações do projeto;

Uma base decisória tecnocrática em que a participação dos idosos ocupou um plano secundário, apenas voltada para aspectos operacionais;

Movimento, Porto Alegre, v. 11, n. 3, p. 27-48, setembro/dezembro de 2005 
A definição de prioridades concentrou-se na burocracia, não ocorrendo a descentralização das decisões de forma que contemplassem os interesses da população alvo;

As decisões referentes ao projeto se pautaram pelo princípio hierárquico, uma vez que as questões apresentadas aos idosos já estavam definidas nas instâncias superiores de poder;

Ausência de mecanismos institucionais de controle social, dificultando, entre outras coisas, o acompanhamento e a consolidação do que havia sido definido nas reuniões;

As reuniões se constituíam nos únicos espaços de discussão, assumindo um caráter consultivo ou informativo sobre aspectos operacionais referentes aos jogos solidários da terceira idade, indicando que o projeto "Idosos em Movimento," no que se refere a sua concepção ou reorientação, não foi alvo de debate por parte da população envolvida.

Não obstante às dificuldades apresentadas, é importante chamar a atenção para um aspecto positivo que diz respeito ao direcionamento pedagógico das ações pautadas numa postura não competitiva, apesar de a prioridade estabelecida pelo Governo apontar na direção do esporte de rendimento.

Apesar de o projeto aparentemente não estar favorecendo o aprendizado democrático com vistas ao exercício da cidadania, é inegável que tem propiciado acesso a novas vivências coletivas, podendo se constituir em um elemento mobilizador de novas possibilidades.

Concluindo, observamos que, para compreender o processo de formulação, implementação e gestão das políticas públicas, foi indispensável estabelecer como foco central da atenção a relação Estado-sociedade. A atenção a essa relação permitiu apreender o caráter não linear que conforma o aparelho de Estado na sua articulação com a sociedade. Essa perspectiva possibilitou a identificação dos limites e das possibilidades das políticas públicas enquanto instrumento democrático de participação social.

Movimento, Porto Alegre, v. 11, n. 3, p. 27-48, setembro/dezembro de 2005 


\begin{abstract}
The relationship between government and society in the policy management of sports and leirsure in Pernambuco State Government - 1999-2001: analysing the "Old People in Movement" project

Abstract: The present study was developed within the masters degree area in Political Sciences; the aim of the work is the analysis of the State-society relationship in the process of formulation, implementation and management of sports and leisure policies in Pernambuco State Government, from the period of 1999 to 2001. It tackles the society's participation in the decisory processes of introduction, implementation and management of sport and leisure policies, through the consideration that the adoption of the participative democracy mechanisms in the management of policies is constituted of innovative elements and contributes to the redefinition of the State-society relationship. However, the conclusions of the study pointed out a distance between the Government's participative proposal and what actually ocurred in the level of the concrete practice of the "Old People in Movement" project.

Keywords: democracy, participation, sports policies.
\end{abstract}

La Relación Gobierno y Sociedad en la Gestión de
La Política Pública de Deportes y Ocio en EI
Gobierno del Estado de Pernambuco - 1999-2001:
Analisando El Proyecto "Idosos En Movimento"
Resumen: El presente estudio fue desarrollado en el
ámbito de la maestría en Ciencia Política y tuvo como
objetivo el análisis de la relación Estado-sociedad en
el proceso de formulación, implementación y gestión
de la política pública de deporte y ocio en el Gobierno
del Estado de Pernambuco, en el período de 1999 has-
ta 2001. Aborda la cuestión de la participación de la
sociedad civil en los procesos decisorios de
implantación, implementación de gestión de la políti-
ca pública de deporte y del ocio, desde la consideración
de que la adopción de mecanismos de democracia
participativa en la adopción de políticas públicas se
constituyen en elementos innovadores y contribuyen


para la redefinición de la relación Estado-sociedad. Sin embargo, las conclusiones del estudio han indicado un distanciamiento entre la propuesta participativa del Gobierno del Estado y lo que efectivamente ocurrió en el nivel de práctica concreta del proyecto "Idosos em Movimento".

Palabras-clave: democracia, participación, políticas públicas de deporte.

\section{Referências}

AMARAL, Silvia Cristina F. Lazer e Participação Popular. In: Revista Licere n 01 , vol. 03, p, 2000.

AMMANN, Safira Bezerra. Considerações Criticas sobre o Conceito de Participação. In: Revista Serviço Social e Sociedade, n. 5-6, São Paulo, Cortez,1981.

BOBBIO, Norberto. O futuro da democracia: uma defesa das regras do jogo. RJ: Paz e Terra,1986.

BRANDÃO, Assis. Sobre a democracia participativa: Poulantzas, Macpherson e Carole Pateman. In: Revista Serviço Social e Sociedade. N ${ }^{\circ} 54$ p,113-131. Cortez Editora, 1997

CACCIA BAVA, Silvio. Democracia e poder local. In: VILLAS-BOAS, Renata (org) Participação Popular nos governos locais. São Paulo, Pólis, n¹4, 1994.

COUTINHO, Carlos Nelson. Democracia e Socialismo: questões de principio e contexto brasileiro. SP: Cortez Autores Associados, 1992.

A Democracia como valor universal: notas sobre a questão democrática no Brasil. SP: Ciências Humanas, 1989.

DALLARI, Dalmo de Abreu. O que é Participação Política. São Paulo. Brasiliense, 1999

DANIEL, Celso. Gestão local e participação da sociedade. In: VILLAS-BOAS Renata (org) Participação popular nos governos locais. São Paulo, Pólis n 14 , 1994.

DEMO, Pedro. Metodologia Cientifica em Ciências Sociais. $3^{\text {a }}$ ed., São Paulo: Atlas, 1995.

Participação é Conquista: Noções de política social participativa. $4^{\mathrm{a}}$ ed. São Paulo, Cortez,1999.

DIAZ, Bordenave, J.E. O que é participação. São Paulo: Brasiliense, 1994.

DINIZ, Eli. Crise, Reforma do Estado e Governabilidade: Brasil 1985/95, RJ:Editora FGV,1997.

Movimento, Porto Alegre, v. 11, n. 3, p. 27-48, setembro/dezembro de 2005 
EMIR, Sader e Gentili, Pablo (orgs). Pós-neoliberalismo: as Políticas Sociais e o Estado Democrático. RJ: Paz e Terra,1995.

FERREIRA, Rosilda Arruda. A Pesquisa Cientifica nas Ciências Sociais. Recife, Ed. Universitária - UFPE,1998.

FOLHA DE PERNAMBUCO, 02 de fevereiro de 2002

JACOBI, Pedro. Cidadania, Participação e Descentralização. In: Políticas sociais e ampliação da cidadania. RJ. Editora FGV,2000.

JORNAL DO COMÉRCIO, 20 de abril de 2000

JORNAL DO COMÉRCIO. Caderno Especial . 16 de abril de 2000

JORNAL DO COMÉRCIO. Caderno especial de 17 de abril de 2002

LAVAREDA, Antonio e SÁ Constança (orgs). Poder e Voto: luta política em Pernambuco. Recife: FUNDAJ. Editora: Massangana, 1986.

LIMA JÚNIOR, Olavo Brasil de. Trajetórias e Dilemas da Democracia In: Instituições Políticas Democráticas: O segredo da legitimidade. RJ Jorge Zahar Editores, 1997

MACHADO, Fábio Ribeiro. Governo local e participação política: a experiência do "Programa Prefeitura na Comunidade" em Campina Grande -PB (1993-1994). Dissertação de Mestrado em Ciência Política - Centro de Filosofia e Ciências Humanas - UFPE, Recife,2002.

MACPHERSON, Crawford B. A Democracia Liberal: Origens e Evolução. RJ. Zahar Editores,1978.

NOGUeIRA, Marco Aurélio. As Possibilidades da Política: Idéias para a reforma democrática do Estado. São Paulo: Paz e Terra,1998

O ESTADÃO, 09 de abril de 2000

PATEMAN, Carole. Participação e Teoria Democrática. Rio de Janeiro. Paz e Terra,1992.

PERNAMBUCO, Projeto "Idosos em Movimento" 1999-2000

PERNAMBUCO, Diário Oficial. 16 de junho de 1999.

PERNAMBUCO, Calendário das Divisões. 2000, 2001, 2002

PERNAMBUCO, Programa de Governo. s/d

ROSENFIELD, Denis L. O que é Democracia. São Paulo. Brasiliense,1994.

SARTORI, Giovanni. A Teoria da Democracia Revisitada. São Paulo, Ática, 1994, V.1. O debate contemporâneo.

SCHMITTER, Philipe. Perspectivas da democracia no mundo contemporâneo: mais liberal, pré-liberal ou pós-liberal? In: GERSCHMAN, Silvia (org). A miragem

Movimento, Porto Alegre, v. 11, n. 3, p. 27-48, setembro/dezembro de 2005 
da pós-modernidade: democracia e políticas sociais no contexto da globalização. RJ: FIOCRUZ, 1997.

SILVA, Gustavo Tavares da. Democracia representativa e "gestão participativa". In: OLIVEIRA, Marcos Guedes de (org). Política e Contemporaneidade no Brasil. Recife. Bagaço,1997.

SILVA, Gustavo Tavares da. Gestão Pública e Transformação Social. 2002. No prelo.

SILVA, Isa Maria Cavalcanti Dias. Imprensa e Poder: (Im) Parcialidade e Ética na Mídia Impressa nas Eleições $1998 \mathrm{em}$ Pernambuco. Dissertação, Mestrado em Ciência Política - Centro de Filosofia e Ciências Humanas, UFPE - 2002.

STIGGER, Marco P. Administração de parques públicos e Democracia. Um estudo de caso na área de políticas públicas para o lazer numa perspectiva democrática. Dissertação de Mestrado em Educação Física - UGF. RJ.1992.

TEIXEIRA, Elenaldo. O Local e o Global. Limites e Desafios da participação cidadã. São Paulo: Cortez; Recife: EQUIP; Salvador: UFBA,2001.

TOURAINE, Alain. O que é Democracia. Petrópolis. RJ, Vozes,1996.

TRIVINOS, Augusto N.S. Introdução à pesquisa em ciências sociais. A pesquisa qualitativa em educação. São Paulo. Atlas,1990.

ZAIDAN FILHO, Michel. Gestão democrática e participação popular. In: A Pedagogia do Desejo, Sociedade e cultura numa época de exclusão social. Recife. Pindorama,1998.

* Mestre em Ciência Política/UFPE e membro da equipe técnica da Gerência de Esportes - PE. Avenida Bernardo Vieira de Melo, 3255/101, Piedade - Jaboatão dos Esportes - PE. Avenida Bernardo Vieira de Melo, 3255/101, Piedade - Jabr

Movimento, Porto Alegre, v. 11, n. 3, p. 27-48, setembro/dezembro de 2005 